\title{
Community Intravenous Therapy Program and a treatment plan for foot infections in persons with diabetes: A clinical perspective
}

\begin{abstract}
John $M$ Embil $M D^{1,2}$, Shurjeel H Choudhri $M D^{1}$, Glenna Germaine $R N^{3}$, Theresa Imlah $R N^{3}$, Frank Duerksen $\mathrm{MD}^{2,4}$, Marie Darcel $\mathrm{RN}^{2}$, Hank Fong $\mathrm{MD}^{2,5}$, Joshua Koulack $\mathrm{MD}^{2,5}$, Alfred Gin Pharm $\mathrm{D}^{6}$, Sheryl Stern $M D^{7}$, J Neil Simonsen $M D^{1,2}$, Godfrey KM Harding $M D^{1}$, Lindsay E Nicolle $M D^{1,2}$
\end{abstract}

$\mathrm{D}$ iabetes is a multi system disease that can lead to complications such as peripheral neuropathy and peripheral vascular disease. These two complications can synergistically lead to the formation of ulcerations in the feet and lower extremities of people with diabetes. Should an ulceration develop, it may be a self-limited process healing spontaneously, or it may lead to more serious complications, such as infection of the skin, soft tissue, bone, sepsis, and possibly amputation of toes, foot or lower extremity. In 1991, 57\% of all amputations involving lower extremities in Manitoba were in people with diabetes. Lower extremity amputations were 10 times higher among people with diabetes than those without diabetes. In 1991, the prevalence of diabetes in adult Manitobans was as follows: First Nations individuals $12 \%$ males and 20\% females; non-First Nations individuals $7 \%$ males and $6.4 \%$ females. The Manitoba Health Services Commission record for 1993 to 1994 show 16\% of lower ex- tremity amputations in Manitoba were among First Nations individuals, and $84 \%$ were among non-First Nations individuals (J Blanchard, personal communication).

Despite great advances made in the treatment of diabetes, significant morbidity and mortality still occurs with this disease. Factors which influence the predisposition for infection include neuropathy which may lead to ulcerations; autonomic insufficiency leading to dry, cracked skin that serves as a portal for infection; vasculopathy leading to ischemia and decreased wound healing capacity; and immunopathy as a consequence of altered neutrophil function. These factors, combined with a lack of or inadequate knowledge of diabetes, can lead to serious complications. Thus, it is critical to identify people with diabetes at risk of foot complications and prevent the complications. Unfortunately, some individuals present with a foot complication as their first presentation of diabetes. In all individuals, it is important to treat quickly

\footnotetext{
${ }^{1}$ Departments of Medicine and Medical Microbiology, Section of Infectious Diseases, University of Manitoba; ${ }^{2}$ Health Sciences Centre Diabetic Foot and Complicated Wound Clinic; ${ }^{3}$ Community Intravenous Therapy Program; ${ }^{4}$ Department of Surgery, Section of Orthopedics, University of Manitoba; ${ }^{5}$ Department of Surgery, Section of Vascular Surgery, University of Manitoba; ${ }^{6}$ Department of Pharmaceutical Services, Health Sciences Centre; ${ }^{7}$ Department of Diagnostic Imaging, Section of Nuclear Medicine, University of Manitoba, Winnipeg, Manitoba

Correspondence and reprints: Dr John M Embil, Infection Control Unit, MS 673-820 Sherbrook Street, Health Centre, Winnipeg, Manitoba R3A 1R9. Telephone 204-787-4654, fax 204-787-4699, e-mail jembil@hsc.mb.ca
} 
and effectively the underlying infection, be it skin, soft tissue and/or bone. The goal is to minimize the risk of amputation.

\section{THE COMMUNITY INTRAVENOUS THERAPY PROGRAMME}

The current approaches that exist for providing therapy to people with diabetes with lower extremity infections are:

- oral antimicrobials administered as an outpatient;

- parenteral antimicrobials delivered as an inpatient;

- parenteral antimicrobials delivered as an inpatient therapy but then switched to oral therapy at the time of discharge; or

- parenteral antimicrobials administered through the Community Intravenous Therapy Program (CITP).

Parenteral medications administered in the outpatient setting have been shown to be safe, effective and convenient for individuals who are clinically stable with regard to their underlying disease process. In addition, cost savings are also realized (1-3). The CITP was established in the early 1980 s as an adjunctive measure to patient care to prevent admission to hospital and to facilitate discharge from hospital. Criteri to establish the eligibility of an individual to receive parenteral antimicrobials administered through the CITP are as follows.

- The patient is clinically stable and can be discharged from hospital and requires ongoing parenteral antimicrobial therapy.

- Oral medications are not suitable for treatment of the current infection either because the microorganism that has been recovered from the wound is resistant to currently available oral antimicrobials or the patient is unable to tolerate oral medication.

- The patient must be compliant with non weight bearing, leg elevation and all other aspects of therapy that will be performed as an outpatient.

- More aggressive adjunctive therapy such as additional surgical debridement of skin, soft tissue or bone has either already been performed or is not necessary.

- The patient must be closely followed by his or her physician to ensure that the therapy for the underlying process is achieving the desired results.

- The patient must be compliant with the policies and procedures of the CITP.

- The home and social circumstances must be conducive to receiving therapy through CITP.

- The patient must be emotionally and psychologically prepared to try therapy administered through CITP.

- Telephone access must be available.

- The safety of the CITP team must be ensured when visiting the patient's dwelling.
Each request for the CITP is reviewed on a case by case basis by the CITP team consisting of: CITP nursing staff, pharmacists, pharmacy technicians, and infectious disease consultants. The CITP reserves the right to seek the input of an infectious disease consultant before enrolling a patient on the program.

\section{INFECTIONS IN THE LOWER EXTREMITIES OF PEOPLE WITH DIABETES}

Infections in the lower extremities of people with diabetes can be divided into those which are mild, moderate and severe and may involve skin, soft tissue, and/or bone. Numerous reports outline the management of infections in the lower extremities of people with diabetes (4-9, unpublished data). Uncomplicated lower extremity infections in people with diabetes are usually caused by aerobic Gram-positive cocci and respond well to oral outpatient therapy (4). A variety of antibiotics exist that are well tolerated orally, and can achieve suitable serum and bone levels for the treatment of deep seated infections (10). The management of osteomyelitis in the foot of PWD is more complicated, and numerous approaches have been recommended, ranging from prolonged parenteral therapy to initial parenteral therapy followed by oral antimicrobial therapy (OAT) or exclusively OAT (5-9, unpublished data).

It is important to differentiate between wound infection and colonization. Infections are usually associated with purulent discharge, edema, erythema and occasionally pain, and bacteria may be recovered from the wound base. With colonization, bacteria will be recovered from swabs of the wound base but the other signs of infection are absent. Superficial skin and soft tissue infections may arise as a consequence of direct trauma and contiguous spread of organisms. If the infection is not controlled and the ulceration progresses, the underlying bone may become involved.

Initially, aerobic Gram-positive bacteria such as Staphylococcus aureus and Streptococcus species are the most frequently isolated organisms. As the ulceration persists, more necrotic tissue is present, and Gram-negative and anaerobic bacteria soon predominate in the wound.

Specimens for culture are best obtained from infected tissue that does not communicate with the skin surface. The ideal specimen for culture assessment of infection is a curettage specimen from the base of the ulcer or bone biopsy specimens if osteomyelitis is suspected. If such specimens are not available, cultures of purulent exudate from within the ulcer base or sinuses may be an alternative.

Before appropriate therapy can be provided, it is important to establish the status of the lower extremity of a person with diabetes as it relates to infection. Issues that must be considered are:

- extent of infection - mild, moderate, severe;

- presence of underlying ulcerations;

- presence of neuropathy;

- adequacy of circulation; 
TABLE 1A

Antibiotic therapy for infected ulcerations in the lower extremity of people with diabetes - Skin and soft tissue

\begin{tabular}{|c|c|c|c|c|}
\hline Type of infection & Medication & Dosage $^{+}$ & $\begin{array}{l}\text { Daily cost } \\
(\$)^{ \pm}\end{array}$ & $\begin{array}{l}\text { Total daily } \\
\text { cost }(\$)^{\S}\end{array}$ \\
\hline $\begin{array}{l}\text { Mild infections are deemed to be neither limb nor } \\
\text { life-threatening processes. They are usually associated } \\
\text { with cellulitis surrounding an ulceration. A small amount } \\
\text { of purulent material may be present at the base of the } \\
\text { ulcer. The most likely organisms are aerobic } \\
\text { Gram-positive cocci. Patients with these infections can } \\
\text { frequently be treated as outpatients with oral therapy. }\end{array}$ & $\begin{array}{c}\text { Cloxacillin } \\
\text { Cephalexin } \\
\text { TMP/SMX } \\
\text { Clindamycin } \\
\text { Amoxicillin-clavulinic acid }\end{array}$ & $\begin{array}{l}500 \mathrm{mg} \text { po qid } \\
500 \mathrm{mg} \text { po qid } \\
1 \mathrm{ds} \text { po bid } \\
300 \mathrm{mg} \text { po qid } \\
500 / 125 \mathrm{mg} \text { po tid }\end{array}$ & $\begin{array}{l}1.03 \\
1.50 \\
0.27 \\
7.51 \\
4.57\end{array}$ & $\begin{array}{l}\text { As per daily } \\
\text { cost }\end{array}$ \\
\hline \multicolumn{5}{|l|}{$\begin{array}{l}\text { Moderate infections can range from plantar abscesses to } \\
\text { more significant cellulitis with tissue necrosis and deep } \\
\text { seated infection. Antimicrobial regimens should be } \\
\text { effective against staphylococci, streptococci, anaerobes, } \\
\text { and common Enterobacteriaceae species. }\end{array}$} \\
\hline $\begin{array}{l}\text { Patients who are not toxic can be treated with local } \\
\text { incision and drainage and oral antimicrobial therapy. }\end{array}$ & $\begin{array}{l}\text { TMP/SMX and } \\
\text { metronidazole }\end{array}$ & $\begin{array}{l}1 \text { ds po bid } \\
500 \text { mg po tid }\end{array}$ & $\begin{array}{l}0.27 \\
0.24\end{array}$ & 0.51 \\
\hline & $\begin{array}{l}\mathrm{TMP} / \mathrm{SMX} \\
\text { and clindamycin }\end{array}$ & & $\begin{array}{l}0.27 \\
7.51\end{array}$ & 7.78 \\
\hline & $\begin{array}{l}\text { Ciprofloxacin and } \\
\text { clindamycin }\end{array}$ & $500 \mathrm{mg}$ po bid & $\begin{array}{l}5.01 \\
7.51\end{array}$ & 12.52 \\
\hline & $\begin{array}{l}\text { Ciprofloxacin } \$ \text { and } \\
\text { clindamycin }\end{array}$ & $\begin{array}{l}750 \mathrm{mg} \text { po bid } \\
300 \mathrm{mg} \text { po gid }\end{array}$ & $\begin{array}{r}13.33 \\
7.51\end{array}$ & 20.84 \\
\hline $\begin{array}{l}\text { - Patients who are critically ill or toxic: are best treated } \\
\text { with parenteral therapy until stable, then switch to oral } \\
\text { therapy. }\end{array}$ & $\begin{array}{l}\text { Amoxicillin-clavulinic acid } \\
\text { Managed as per severe infections, } \\
\text { see below }\end{array}$ & $500 / 125 \mathrm{mg}$ po tid & 4.57 & 4.57 \\
\hline \multirow{6}{*}{$\begin{array}{l}\text { Severe infections: Patients with severe diabetic foot } \\
\text { infections have limb- or life-threatening infections } \\
\text { requiring immediate hospitalization and parenteral } \\
\text { antimicrobial therapy. Early surgical debridement and } \\
\text { drainage of abscesses is critical. }\end{array}$} & $\begin{array}{l}\text { Clindamycin and } \\
\text { gentamicin } \\
\text { Cefotetan }\end{array}$ & $\begin{array}{l}\text { IV } 600 \mathrm{mg} \text { Q8h } \\
\text { IV } 80 \mathrm{mg} \text { Q } 8 \mathrm{~h} \\
\text { IV } 2 \text { g Q12h }\end{array}$ & $\begin{array}{l}40.00 \\
12.00 \\
60.00\end{array}$ & $\begin{array}{l}52.00 \\
\text { As per daily } \\
\text { cost }\end{array}$ \\
\hline & $\begin{array}{l}\text { Cefazolin and } \\
\text { metronidazole }\end{array}$ & $\begin{array}{l}\text { IV } 2 \text { g Q8h } \\
\text { IV } 500 \text { mg Q8h }\end{array}$ & $\begin{array}{r}18.00 \\
4.59\end{array}$ & 22.59 \\
\hline & $\begin{array}{l}\text { Piperacillin and } \\
\text { tazobactam }\end{array}$ & IV 3.375 g Q6h & 63.60 & 63.60 \\
\hline & $\begin{array}{l}\text { Clindamycin and } \\
\text { ceftriaxone }\end{array}$ & $\begin{array}{l}\text { IV } 600 \text { mg Q8h } \\
\text { IV } 1 \text { g O24h }\end{array}$ & $\begin{array}{l}40.00 \\
34.00\end{array}$ & 67.60 \\
\hline & Imipenem/cilistatin & IV 500/500 mg Q6h & 97.52 & 97.52 \\
\hline & Meropenem & IV 1 g Q8h & 141.84 & 141.84 \\
\hline
\end{tabular}

*If in doubt about the most appropriate antibiotic for the management of the diabetic foot infection, discussion with an infectious disease consultant may be prudent. ${ }^{+}$Before antimicrobials are used in the person with diabetes, an evaluation of renal function must be undertaken to best guide appropriate dosing. This is particularly important with the aminoglycosides. Dosages shown are for normal renal function. If using aminoglycosides it is imperative that the renal function and drug levels be monitored closely.; ;Approximate daily cost for oral therapy excludes the dispensing fee. These are 1998 costs based upon the Manitoba Drug Benefits and Interchangeability Formulary and the Manufacturer's recommended dosing regimen and listed price. sIn some instances, a higher dose of ciprofloxacin may be necessary. Other quinolone antimicrobial agents may be considered as alternatives, but a review of product monographs is necessary to establish optimal doses. ds Double strength; IV intravenous; po By mouth; TMP/SMX Trimethoprim/sulfamethoxazole

- $\quad$ presence of underlying osteomyelitis; and

- adjunctive measures.

The suggestions that follow for investigations, dressings and therapeutic interventions have been kept as simple as possible. The suggestions are to be used in conjunction with appropriate management of the underlying diabetes and other metabolic abnormalities.

Extent of infection: Tables $1 \mathrm{~A}$ and $1 \mathrm{~B}$ summarize the classification of infections in the lower extremities of people with diabetes and provides treatment suggestions. It is important to recall that it is advisable to use wound or bone cultures to help guide antimicrobial choices. Figure 1 provides a simplified algorithm to help determine the most appropriate treatment regimens for patients presenting with diabetic foot infections. Neuropathy: A history of foot numbness, lack of sensation, prior amputation of the contralateral lower extremity or toes on either extremity, and prior foot ulcerations should raise the suspicion that an individual lacks protective sensation. Callouses may result from unrelieved pressure and may also lead to ulcerations due to undermining of the underlying skin. The loss of pain perception due to neuropathy leads to increased susceptibility to mechanical and thermal trauma. Injury, ulcerations and subsequent infection may go unnoticed in the insensate foot. At every office visit, people with diabetes should be asked whether they are inspecting their feet regularly, and whether they have a current ulceration of their feet.

Adequacy of circulation: For resolution of infection and promotion of wound healing, adequate circulation is necessary. If pulses are not palpable in the lower extremity, it is important to obtain an estimate of the adequacy of circulation. The "ankle brachial index' is a noninvasive method where comparison of 
TABLE 1B

Antibiotic therapy for infected ulcerations in the lower extremity of people with diabetes

\begin{tabular}{|c|c|c|c|c|}
\hline Type of infection & Medication & Dosage $^{+}$ & $\begin{array}{l}\text { Daily cost } \\
\qquad(\$)^{\ddagger}\end{array}$ & $\begin{array}{l}\text { Total daily } \\
\text { cost }(\$)^{\S}\end{array}$ \\
\hline \multirow{10}{*}{$\begin{array}{l}\text { Osteomyelitis is a frequent complication of diabetic foot } \\
\text { ulcerations. Antimicrobial choices must be guided by } \\
\text { culture data. Monotherapy may be used based upon } \\
\text { clinical assessment and culture results. } \\
\text { - Oral therapy: Osteomyelitis may be managed with } \\
\text { long term oral antimicrobial therapy with agents that } \\
\text { are well absorbed from the gastrointestinal tract and } \\
\text { have good distribution to bone and tissue. }\end{array}$} & TMP/SMX and & 1 ds po bid & 0.25 & 0.65 \\
\hline & metronidazole & $500 \mathrm{mg}$ po tid & 0.40 & \\
\hline & $\mathrm{TMP} / \mathrm{SMX}$ and & $1 \mathrm{ds}$ po bid & 0.25 & 6.30 \\
\hline & clindamycin & 300 mg po gid & 6.05 & \\
\hline & Amoxicillin-clavulinic acid & 500/125 mg p tid & 4.20 & 4.20 \\
\hline & metronidazole & $500 \mathrm{mg}$ po tid & 5.02 & 5.42 \\
\hline & Ciprofloxacin and & $500 \mathrm{mg}$ po bid & 0.40 & \\
\hline & clindamycin & $300 \mathrm{mg}$ po qid & 5.02 & 11.07 \\
\hline & Ciprofloxacin ${ }^{\S}$ and & $750 \mathrm{mg}$ po bid & 6.05 & \\
\hline & clindamycin & $300 \mathrm{mg}$ po gid & 9.48 & 15.53 \\
\hline \multirow{11}{*}{$\begin{array}{l}\text { Parenteral therapy: In some cases, parenteral therapy } \\
\text { may be necessary. Although multiple parenteral } \\
\text { regimens exist, only those which may be easily } \\
\text { administered through the Community Intravenous } \\
\text { Therapy Program are noted here. Aminoglycoside- } \\
\text { based regimens are avoided for prolonged treatment } \\
\text { courses because of potential complications. The } \\
\text { duration of parenteral therapy is guided by clinical } \\
\text { response and every attempt should be made to use } \\
\text { oral regimens when possible. }\end{array}$} & Cefazolin and & IV 2 g Q8h & 6.05 & \\
\hline & metronidazole & IV 500 mg Q8h & 18.00 & 22.59 \\
\hline & & or $500 \mathrm{mg}$ po tid & 4.59 & 18.40 \\
\hline & & IV 2 g Q12h & 0.40 & \\
\hline & Cefotetan & IV 3.375 g Q6h & & \\
\hline & $\begin{array}{l}\text { Piperacillin and } \\
\text { tazobactam }\end{array}$ & IV 600 mg Q8h & 63.60 & 63.60 \\
\hline & Clindamycin and & IV 1 g Q24h & 40.00 & 67.60 \\
\hline & ceftriaxone & IV 1 g Q24h & 34.00 & \\
\hline & Ceftriaxone and & IV 500 mg Q8h or & 34.00 & 38.99 \\
\hline & metronidazole & 500 mg po tid & 4.59 & \\
\hline & & & 0.40 & \\
\hline
\end{tabular}

*If in doubt about the most appropriate antibiotic for the management of the diabetic foot infection, discussion with an infectious disease consultant may be prudent. ${ }^{\dagger}$ Before antimicrobials are used in the person with diabetes, an evaluation of renal function must be undertaken to best guide appropriate dosing. This is particularly important with the aminoglycosides. Dosages shown are for normal renal function. If using aminoglycosides it is imperative that the renal function and drug levels be monitored closely. ${ }^{\ddagger}$ Approximate daily cost for oral therapy excludes the dispensing fee. These are 1998 costs based upon the Manitoba Drug Benefits and Interchangeability Formulary and the Manufacturer's recommended dosing regimen and listed price. $\$$ In some instances, a higher dose of ciprofloxacin may be necessary. Other quinolone antimicrobial agents may be considered as alternatives, but a review of product monographs is necessary to establish optimal doses. ds Double strength; IV intravenous; po By mouth; TMP/SMX Trimethoprim/sulfamethoxazole

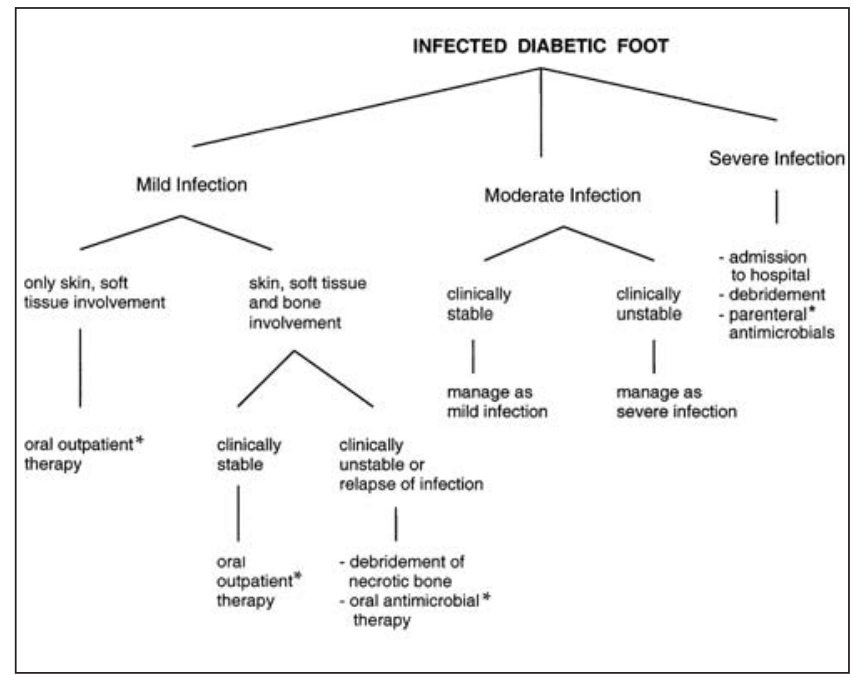

Figure 1) Algorithm for the selection of antimicrobial therapy. *See Table 1 for antimicrobial choices either the dorsalis pedis or posterior tibial blood pressure is made to the brachial artery blood pressure. Ankle brachial indexes below 0.5 indicate significant reduction in large blood vessel flow, corresponding with severe peripheral vascular disease (11). Ratios of less than 0.3 are associated with rest pain and limb-threatening ischemia (12). In some clinical presentations, ischemia is suspected even where an adequate ankle brachial index has been documented. This may be due to noncompressible vessels as a consequence of calcification (13). It may be prudent to proceed to angiography in these situations.

Status of bone: The diagnosis of osteomyelitis in the person with diabetes with a foot infection is difficult because it may be difficult to use standard clinical criteria. Individuals with soft tissue infections or skin ulcerations that have been present for several weeks are at high risk of contiguous bone involvement, particularly if these lesions are located over a bony prominence (5). Clinical findings that can be used to determine the pres-

TABLE 2

Imaging techniques for identifying osteomyelitis in the feet of people with diabetes

\begin{tabular}{lccc}
\hline Test modality & Mean sensitivity (range) (\%) & Mean specificity (range) (\%) & Positive predictive value (\%) \\
\hline Plain radiography & $60(28-93)$ & $60(50-92)$ & $74-87$ \\
Technicium bone scan & $86(68-100)$ & $45(0-79)$ & $43-87$ \\
Indium white blood cell scan & $89(45-100)$ & $78(29-100)$ & $75-85$ \\
Magnetic resonance imaging & $99(29-100)$ & $83(71-100)$ & $50-100$ \\
\hline
\end{tabular}

Modified from references $(6,16,18-20)$ 
TABLE 3

Diabetic foot ulcer management suggestions

\begin{tabular}{|c|c|}
\hline Grade & Wagner classification \\
\hline Grade 0 & $\begin{array}{l}\text { Skin intact, no open lesions. Callous } \\
\text { may be present under weight bearing } \\
\text { areas. Callouses may act as abnormal } \\
\text { pressure points leading to ulceration } \\
\text { of the underlying skin. Nonblanching } \\
\text { erythema may be present as a } \\
\text { consequence of unrelieved pressure }\end{array}$ \\
\hline
\end{tabular}

Grade 1 Superficial skin ulceration, often seen under high pressure areas (metatarsal heads, toes)

Grade 2 Deeper ulceration, usually associated with infection/cellulitis. The ulceration does not extend to bone

Grade 3 Ulcerations extend to deeper tissue layers such as bone. If bone can be probed at the base of an ulceration, it is likely that osteomyelitis is present.

Grade 4 Localized gangrene (toes, forefoot, heel)

Grade 5 Gangrene of entire foot

\section{Management suggestion}

- Callouses should be pared

- Footwear should be fitted for proper weight displacement

- Callouses should be pared to expose the ulcer base.

- Deep swabs or currettage specimen from ulcer base should be taken for bacterial culture to determine the etiology of underlying infection.

- Clean with saline for 5 to 10 mins with dressing changes daily.

- A hydroactive gel (Duoderm [Hydroactive Gel, Convatec, Montreal, Quebec], Intrasite [Intrasite Gel, Smith and Nephew, Lachine, Quebec]or Tegagel [3M, London, Ontario]) covered by a clean gauze is the simplest approach, saline wet to dry dressings are an alternative.

- Should necrotic tissue be present or the wound be dirty, a gauze moistened with one-quarter strength Eusol can be applied twice daily. If Eusol is used, petroleum jelly must be used to protect the skin surrounding the ulceration. Prolonged use of Eusol must be avoided because it may be toxic to granulation tissue.

- Once the wound is clean and provided that granulation tissue is present, hydroactive gel should be substituted for the Eusol.

- Infected ulcers (cellulitis) will require systemic antibiotics. Antibiotic choice can be guided by appropriately collected swabs for culture.

- Radiographs should be obtained to exclude unsuspected bone infection (if this is detected, the ulcer should be considered a grade 3 lesion).

- Pressure relief is essential for the healing of these lesions; this can be accomplished by appropriate footwear, crutches, wheelchairs and casting. If casting is considered, it must be applied by an experienced individual and monitored on a regular basis.

- These ulcers are deeper and often penetrate to subcutaneous tissue with local infection but have no bony involvement. These ulcerations are managed in a fashion similar to grade 1 lesions.

- Some advocate aggressive surgical debridement of all infected bone; however, in many cases, osteomyelitis may be treated conservatively.

- Appropriate systemic antimicrobials must be administered for a prolonged period. Antimicrobials may be administered orally in most patients. Only in very rare instances is the home intravenous therapy program is necessary for the management of osteomyelitis in individuals with diabetes.

- Noninvasive assessment of the adequacy of peripheral circulation (ankle brachial index) should be performed.

- Radiographs should be obtained of the affected foot to rule out foreign bodies and gas, and to establish the magnitude of bony involvement.

- A surgical opinion may be necessary if vascular insufficiency is present or if resection of infected bone and gangrenous material is necessary.

- Management should be as for a grade 3 ulceration.

- An urgent noninvasive assessment of a peripheral circulation and vascular surgical opinion are indicated; an angiogram may be needed. Angioplasty or by-pass surgery may be required if a suitable stenotic lesion is demonstrated on angiography.

- Some individuals may have vascular disease that is not amenable to any revascularization procedure. Local surgery to remove gangrenous tissue may be attempted; however, single ischemic toes should be kept dry and may be left to mummify and auto-amputate.

- Patients with more extensive gangrene require urgent assessment as outlined for grade 4 lesions.

- These individuals will require control of diabetes and infection, and will require foot-preserving surgery or amputation, guided by the level and adequacy of circulation. ence of osteomyelitis are that the larger and deeper an ulceration is, the more likely an underlying osteomyelitis will be present (14). In another study, all ulcers in which bone was exposed either visibly or by probing had underlying osteomyelitis (15). Imaging techniques for the diagnosis of osteomyelitis vary with a wide range of sensitivity, specificity and positive predictive value. The plain radiograph, for instance, will only demonstrate bony abnormalities related to osteomyelitis 10 to 20 days after the bone infection has occurred and $40 \%$ to $70 \%$ of the bone has been resorbed (5). Although the plain radiograph findings are not pathognomonic for infection, a diagnosis of probable osteomyelitis can be made when classic radiological findings are noted (5). If plain radiographs are being used for the diagnosis of osteomyelitis, it is important to obtain a base- 
Please complete with Utilization Checklist the information requested. This will provide a base line for ongoing monitoring.

1. Location of infection:

2. Type of infection: skin/soft tissue/underlying sore:

3. Allergies to medications (specify type of reaction):

4. Able to take oral medication: Yes No

5. Base line: Complete blood count: $\mathrm{HgB}$ : ESR: $\mathrm{HgB}$ A1C: WBC: Ptl:

6. Culture report:

Bone biopsy:

Superficial swab:

Deep swab:

Tissue from operating room:

Blood culture:

7. Renal Function:

Urea:

Creatinine:

24 hour urine for creatinine clearance (if available) :

8. X-ray of affected extremity:

9. Reason why CITP is requested:

10. Expected duration of therapy:

11. Does patient need home care for wound care:

12. Other medications:

Figure 2) Community Intravenous Therapy Program (CITP) form for foot infections in people with diabetes. HgB Hemoglobin; HgB A1C Glycosylated hemoglobin; WBC White blood cell count; ptl Platelets, ESR Erythrocyte sedimentation rate

line radiograph and then follow it with another plain radiograph in 10 to 21 days to determine whether the typical bony abnormalities are present. Table 2 demonstrates the available imaging techniques for identifying osteomyelitis in the foot of people with diabetes. Initial screening investigations for osteomyelitis include the erythrocyte sedimentation rate and a plain radiograph of the affected area. A three-phase technetium bone scan (Tc-99m MDP) is sensitive for diagnosing osteomyelitis but suffers from poor specificity in diabetic foot infections due to frequent false positives from overlying soft tissue hyperemia (16). The simplest approach is to obtain a baseline $\mathrm{x}$ ray and then repeat it in two to three weeks. In that intervening period, osteomyelitis should be visible radiographically. If clinical suspicion persists, a bone scan combined with a gallium scan or white blood cell study, if equivocal, may be warranted (16). The addition of gallium or white blood cell scanning to the three-phase bone scan yields improved specificity while maintaining sensitivity.

Adjunctive therapy: In addition to the antimicrobial therapy outlined in Tables $1 \mathrm{~A}$ and $1 \mathrm{~B}$, ongoing care of the wound or foot ulcer is necessary. Table 3 demonstrates some suggestions for the management of these wounds. It is not clear what role, if any, topical antimicrobials play in the management of foot lesions of people with diabetes. There are insufficient, well controlled data to support the routine use of topical enzymatic debriding agents, such as collagenase, at this time.

Duration of therapy: Based upon the preceding considerations, antimicrobial therapy can be initiated as outlined in Table 1. The vast majority of mild infections can be treated with a two-week course of appropriate culture-guided OAT (4). If a culture is not available, empirical therapy will be needed. If an infection is acute and the ulcer has been present for less that two to three weeks, the most likely pathogens are $S$ aureus and Streptococcus species (groups A and B). Therapy with a betalactam, such as cloxacillin or cephalexin, would be appropriate (Table 1). If the lesion has been present for a more prolonged period, the presence of a mixed flora of microorganisms is likely and empirical therapy with trimethoprim/sulphamethoxazole or cephalexin would be appropriate (Table 1). Treatment choices are shown in Table 1. Moderate infections range from those in which the patients are not toxic and can be treated with local incision, drainage and OAT, to those in patients who are critically ill or toxic and who require incision, drainage, debridement and parenteral therapy.

In those individuals with severe infections, parenteral therapy is necessary. Once the acute infection has been stabilized and an assessment of whether an underlying bone infection is present, it is prudent to step down the patient's care to oral 


\begin{tabular}{|c|c|c|c|}
\hline \multicolumn{2}{|c|}{ Nursing Diagnosis: ${ }^{23}$} & \multicolumn{2}{|c|}{$\begin{array}{l}\text { Altered lower extremity tissue, perfusion related to insufficient } \\
\text { circulation secondary to diabetes mellitus. } \\
\text { Potential for sepsis. } \\
\text { Potential for infection transmission. }\end{array}$} \\
\hline Nursing Goal: & \multicolumn{3}{|c|}{$\begin{array}{l}\text { Patients with diabetes being treated for lower extremity infections will safely } \\
\text { manage the administration of prescribed therapy, and will not succumb to } \\
\text { relapses of infection. }\end{array}$} \\
\hline \multicolumn{4}{|c|}{$\begin{array}{r}\text { Outcome Criteria: } \\
\stackrel{\bullet}{\bullet} \\
\bullet \\
\bullet\end{array}$} \\
\hline \multicolumn{2}{|c|}{ Nursing Interventions } & Nursing Care & \begin{tabular}{|c|} 
Nurse Alert \\
\end{tabular} \\
\hline Assessment & & $\begin{array}{l}\text { - Review the wound and/or area } \\
\text { of infection daily with dressing } \\
\text { changes } \\
\text { - Note changes in discharge, } \\
\text { odor, color of lower extremity, } \\
\text { pain, fluctuance, sinus tracts } \\
\text { - Record oral temperature } \\
\text { - Record blood sugar readings } \\
\text { - Note whether pulses were } \\
\text { present } \\
\text { - Monitor venous access site for } \\
\text { signs of: infection, phlebitis, } \\
\text { leakage, venous catheter } \\
\text { occlusion }\end{array}$ & $\begin{array}{l}\text { - A relapse in infection can manifest } \\
\text { with new fever; oral temperature } \\
>38.5 \mathrm{C} \text {, elevated blood glucose } \\
\text { readings, erythema on the affected } \\
\text { limb, purulent discharge, a new or foul } \\
\text { odor, new pain and discomfort in the } \\
\text { affected limb } \\
\text { - A lower extremity which becomes } \\
\text { pulseless, pale and painful is a } \\
\text { warning that the limb is in peril. THIS } \\
\text { IS A MEDICAL EMERGENCY. This } \\
\text { patient needs urgent medical } \\
\text { attention. }\end{array}$ \\
\hline \multicolumn{2}{|l|}{ Asepsis } & $\begin{array}{l}\text { - Good hand washing, blood and } \\
\text { body fluid precautions, aseptic } \\
\text { technique for intravenous } \\
\text { catheter maintenance } \\
\text { - Monitor for malaise, weakness, } \\
\text { easy fatigability and signs of } \\
\text { local and systemic infection } \\
\text { - Communicate findings with the } \\
\text { physician }\end{array}$ & $\begin{array}{l}\text { - Hand washing is the most effective } \\
\text { method for preventing disease } \\
\text { transmission. Follow standard CITP } \\
\text { protocols for care of all intravenous } \\
\text { catheters }\end{array}$ \\
\hline \multicolumn{2}{|c|}{ Initiate Health Teaching } & $\begin{array}{l}\text { - Assess contributing factors } \\
\text { - Review patients current } \\
\text { understanding } \\
\text { - Promote activities and health } \\
\text { behaviour that will improve } \\
\text { wound healing, peripheral } \\
\text { circulation } \\
\text { - Emphasize: appropriate diet, } \\
\text { foot care, compliance with } \\
\text { mediations and prescribed } \\
\text { therapies }\end{array}$ & $\begin{array}{l}\text { - Avoid applying heating pads, or water } \\
\text { bottles to lower extremities as heat } \\
\text { may not be appreciated in the } \\
\text { neuropathic limb leading to tissue } \\
\text { trauma }\end{array}$ \\
\hline
\end{tabular}

Figure 3) Nursing care plan for lower extremity infections in people with diabetes.

therapy if possible. If an underlying osteomyelitis is present, in the vast majority of cases, the infection can be treated with a prolonged course of antimicrobial therapy appropriately guided by culture data as outlined in Tables $1 \mathrm{~A}$ and $1 \mathrm{~B}$.

The ideal duration of therapy for the treatment of osteomyelitis in the lower extremities of people with diabetes has not been precisely established. Surgical debridement, where necessary, must be adequate to remove devitalized tissue. It has been traditionally recommended that four to six weeks of parenteral therapy are sufficient. These recommendations have been based upon experimental animal models (19). However, combined regimens of parenteral therapy followed by prolonged oral therapy have had good results as have prolonged courses of OAT (20). Prolonged appropriate OAT may be an alternative to parenteral therapy for osteomyelitis (6-10, unpublished data). The decision that remains is whether to use parenteral antimicrobial therapy administered at home or whether the patient should receive an oral antimicrobial that is well absorbed from the gastrointestinal tract and which achieves high serum levels $(10,21)$. Selecting the most appropriate antimicrobial is important because prolonged duration of therapy will be required (22). It is believed that for most antimicrobials, the concentrations achieved in bone are similar to those achieved in serum $(19,21,22)$. The decision to use OAT for the treatment of osteomyelitis must take into account that regular follow-up of the patient with regards to their lower extremity is critical. It is important to follow the erythrocyte sedimentation rate as a marker of decreasing inflamma- 
tion and serial plain radiographs to ensure that bone healing and remodelling is occurring. These measures can help guide the total duration of therapy and detect relapses. If the patient does not improve or deteriorates after the initiation of OAT, re-evaluation of the treatment is critical to ensure that the appropriate therapy has been selected according to the culture data or perhaps aggressive debridement of the bone is necessary as is ensuring adequacy of circulation.

\section{USING THE CITP}

Before a person with diabetes with a lower extremity infection is enrolled in the CITP, the checklist in Figure 2 is completed to ensure that all the necessary background information is available. Once a patient is enrolled into the CITP, the program staff work in conjunction with the Home Care and Victorian Order of Nurses Visiting Services to ensure that the patient is managing with the prescribed therapy and that the intravenous catheter is working correctly. The routine visits are also an ideal opportunity for ongoing evaluation of the lower extremity infection and wound. Figure 3 demonstrates the nursing care plan.

\section{CONCLUSIONS}

Although persons with diabetes, and acute skin and soft tissue infections can be managed in hospital, they may also be managed through the CITP provided that the patient satisfies all of the criteria for participation. For osteomyelitis, which is a chronic and indolent process, our experience has shown that osteomyelitis of the foot has been successfully treated with OAT in the vast majority of cases $(80.2 \%)$ which were reviewed in a large retrospective study. In this study, 116 foci of osteomyelitis were considered in 325 persons with diabetes who presented to a multidisciplinary foot clinic for assessment and management. There were 10 foci of osteomyelitis which failed to heal with OAT. The reason for failure was that the microorganisms were resistant to the available oral antimicrobials in six patients, patient noncompliance with OAT occurred with two patients, one patient developed an allergy to the oral antimicrobials and one patient had a profoundly ischemic limb that subsequently went to amputation (unpublished data). It is, therefore, important that all parameters of the patient's lower extremity and patient compliance be considered before enrolling an individual in an ambulatory intravenous therapy program. Prolonged OAT may be an alternative to parenteral therapy for the management of osteomyelitis in the foot of the person with diabetes.

ACKNOWLEDGEMENTS: The authors thank Mrs Sandra Brown and Mrs Carolyn Cooper for preparing this document.

\section{REFERENCES}

1. Grayson ML, Silvers J, Turnidge J. Home intravenous antibiotic therapy: A safe and effective alternative to inpatient therapy. Med J Aust 1995;162:249-53.

2. Milkovich G. Cost and benefits. Hosp Pract 1993;3(Suppl 1):39-43.

3. Eisenberg JN, Kitz DS. Savings from outpatient antibiotic therapy for osteomyelitis: Economic analysis of a therapeutic strategy. JAMA 1986;225:1584-8.

4. Lipsky BA, Pecoraro RE, Larson SA, et al. Outpatient management of uncomplicated lower-extremity infections in diabetic patients. Arch Intern Med 1990;150:790-7.

5. Lipsky BA. Osteomyelitis of the foot in diabetic patients. Clin Infect Dis 1997;25:1318-26.

6. Pittet D, Wyssa B, Herter-Clavel C, et al. Outcome of diabetic foot infection treated conservatively. A retrospective cohort study with long-term follow-up. Arch Intern Med 1999;159:851-6.

7. Wilson $\mathrm{KH}$, Kauffman CA. Oral antibiotic therapy for osteomyelitis of the foot in diabetic patients. South Med J 1985;78:223-4.

8. Venkatesan P, Lawn S, MacFarlane RM, et al. Conservative management of osteomyelitis in the feet of diabetic patients. Diabetic Med 1997;14:487-90.

9. Peterson LR, Lissack LM, Canter K, et al. Therapy of lower extremity infections with ciprofloxacin in patients with diabetes mellitus, peripheral vascular disease or both. Am J Med 1989;86:801-8.

10. MacGregor RR, Graziani AL. Oral administration of antibiotics: A rational alternative to the parenteral route. Clin Infect Dis 1997;24:457-67.

11. Orchard TJ, Strandness DE Jr on behalf of the participants. Assessment of peripheral vascular disease in diabetes. Report and recommendation of an International Work Shop sponsored by the American Heart Association and the American Diabetes Association, September 18 to 20 1992. New Orleans, Louisiana. Circulation 1993;88:819-28.

12. Barner MG, Kaiser GC, William VL. Blood flow in the diabetic leg. Circulation 1971;43:391-4.

13. Takolander R, Rauwerda JA. The use of non-invasive vascular assessment in diabetic patients with foot lesions. Diabetic Med 1996;13:539-42.

14. Newman LG, Waller J, Palestro CJ, et al. Unsuspected osteomyelitis in diabetic foot ulcers: Diagnosing and monitoring by leukocyte scanning with indium In $^{111}$ oxyquinonlone. JAMA 1991;226:1246-51.

15. Grayson ML, Gibbons GW, Balogh K, et al. Probing to bone in infected pedal ulcers. JAMA 1995;273:721-3.

16. Keenan AM, Tindel NL, Alavi A. Diagnosing pedal osteomyelitis in diabetic patients using current scintigraphic techniques. Arch Intern Med 1989;149:2262-6.

17. Schauwecker DS. Osteomyelitis: diagnosis with In-111-labled leukocytes. Radiology 1989;171:141-6.

18. Shults DW, Hunter GC, McIntyre KE, et al. Value of radiographs and bone scans in determining the need for therapy in diabetic patients with foot ulcers. Am J Surg 1989;158:525-30.

19. Norden $\mathrm{CW}$. Lessons learned from animal models of osteomyelitis. Rev Infect Dis 1988;10:103-9.

20. Bamberger DM, Duas GP, Gerding DM. Osteomyelitis in the feet of diabetic patients. Am J Med 1987;83:653-9.

21. Fitzgerald RH. Antibiotic distribution in normal and osteomyelitic bone. Orthop Clin North Am 1984;15:537-46.

22. Gentry LO, Rodrigues GG. Oral ciprofloxacin compared with parenteral antibiotics in the treatment of osteomyelitis. Antimicrob Agents Chemother 1990;34:40-3.

23. Perioperative nursing. In: Nettina SM, ed. The Lippincott Manual of Nursing Practice, 6th edn. Philadelphia: JB Lippincott Company, 1996. 